Check for updates

Cite this: RSC Adv., 2017, 7, 46900

Received 3rd September 2017

Accepted 29th September 2017

DOI: 10.1039/c7ra09793j

rsc.li/rsc-advances

\title{
Clausoxamine, an alkaloid possessing a 1,3- oxazine-4-one ring from the seeds of Clausena lansium and the anti-obesity effect of lansiumamide $\mathrm{B} \dagger$
}

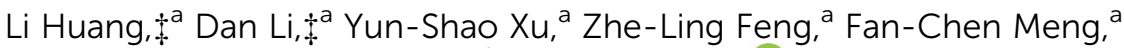 \\ Qing-Wen Zhang, ${ }^{a}$ Li-She Gan ${ }^{b}$ and Li-Gen Lin (D) *a
}

\begin{abstract}
A novel alkaloid, clausoxamine (1), which possesses an unprecedented 1,3-oxazinan-4-one ring, was isolated from the seeds of Clausena lansium, along with six known analogues. The structure and absolute configuration of 1 were established on the basis of detailed NMR and HRESIMS analysis, as well as comparison of its experimental and TD-DFT calculated ECD spectra. A proposed biosynthetic pathway was predicted for compound 1. The major alkaloid, lansiumamide B, was found to reduce fat mass gain and improve insulin sensitivity on high fat diet treated mice, which might be a potential antiobesity and insulin sensitizing agent.
\end{abstract}

\section{Introduction}

Obesity is approaching epidemic proportions worldwide, resulting in higher risks of insulin resistance, hyperlipidemia, and cardiovascular diseases. ${ }^{\mathbf{1 , 2}}$ Over nutrition often leads to expansion of visceral adipose tissue, elevated triglycerides and low-density lipoprotein (LDL), and decreased high-density lipoprotein (HDL), which eventually causes type 2 diabetes. The US Food and Drug Administration approved anti-obesity drugs, either appetite suppressors or pancreatic lipase inhibitors, always have unpleasant adverse effects. ${ }^{3}$ Alternatively, natural products have attracted considerable attention in the discovery and development of new anti-obesity drugs due to their safety and efficacy.

Clausena lansium Skeels (Rutaceae) is widely cultivated in southern China and Southeast Asia, and the edible fruit, called wampee, is highly aromatic and pleasantly sweet. In traditional medicines, the leaves and roots of $C$. lansium have been used for treatment of cough, asthma, dermatological disease, and gastro-intestinal diseases. The seeds have been used to treat acute and chronic gastro-intestinal inflammation and ulcers. ${ }^{4}$ Extensive phytochemical investigations on different parts of this plant have revealed the presences of amide alkaloids,

${ }^{a}$ State Key Laboratory of Quality Research in Chinese Medicine, Institute of Chinese Medical Sciences, University of Macau, Macao 999078, People's Republic of China. E-mail: ligenl@umac.mo

${ }^{b}$ College of Pharmaceutical Sciences, Zhejiang University, 866 Yuhangtang Road, Hangzhou 310058, People's Republic of China

$\dagger$ Electronic supplementary information (ESI) available: Lipid profile in livers, a listing of NMR, IR and HRESIMS spectra of compound 1, as well as the conformational analysis of compound 1. See DOI: 10.1039/c7ra09793j

\$ These authors contributed equally to this work. carbazole alkaloids, and coumarins with anti-inflammation, anti-oxidation, and anti-cancer properties. ${ }^{5-9}$ In our research for new anti-obesity natural products, one new amide alkaloids with an unprecedented skeleton was identified from the seeds of $C$. lansium, together with six known analogues. Compound 1 possessed an unusual 1,3-oxazine-4-one ring. Herein, the isolation, structure characterization, and proposed biosynthetic pathways of the new compound, as well as anti-obesity effect of lansiumamide B on high-fat diet treated mice, are presented.

\section{Results and discussion}

The EtOAc-soluble fraction of a 95\% ethanol extract of C. lansium was purified by column chromatography over silica gel, Sephadex LH-20 and preparative HPLC to afford seven amide alkaloids, including one new compound (1, Fig. 1) and six known analogues.

Compound 1 was isolated as a white amorphous powder, and its molecular formula was designated as $\mathrm{C}_{18} \mathrm{H}_{17} \mathrm{NO}_{3}$ according to the protonated ion peak at $m / z 296.1261[\mathrm{M}+\mathrm{H}]^{+}$

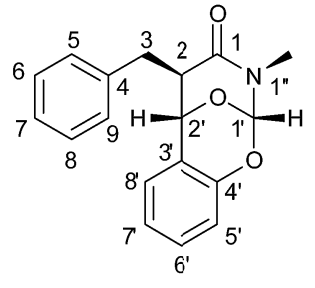

1
2

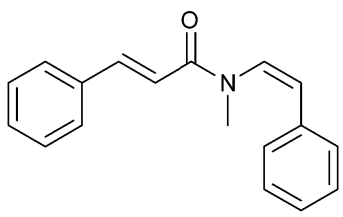

Fig. 1 The structures of clausoxamine (1) and lansiumamide B (2). 
(calcd for $\mathrm{C}_{18} \mathrm{H}_{18} \mathrm{NO}_{3}, 296.1287$ ) in its HRESIMS, requiring eleven degrees of unsaturation. The IR spectrum exhibited absorptions for an amide group $\left(1658 \mathrm{~cm}^{-1}\right)$ and a phenyl group (1491 and $1459 \mathrm{~cm}^{-1}$ ). The ${ }^{13} \mathrm{C}$ NMR and DEPT spectra (Table 1) revealed the presence of 18 carbon resonances encompassing one methyl group, one methylene group, 12 methine groups (including three $\mathrm{sp}^{3}$ carbons and nine aryl carbons), and 4 quaternary carbons (including three aryl carbons and one carbonyl group). The ${ }^{1} \mathrm{H}$ NMR data of $\mathbf{1}$ (Table 1), with the aid of the HSQC data, displayed signals ascribed to one ortho-disubstituted benzene moiety $\left[\delta_{\mathrm{H}} 6.91(\mathrm{dd}, J=8.2,1.1 \mathrm{~Hz}) / \delta_{\mathrm{C}} 117.2\right.$; $\delta_{\mathrm{H}} 7.24(\mathrm{~m}) / \delta_{\mathrm{C}} 130.0 ; \delta_{\mathrm{H}} 6.98(\mathrm{td}, J=7.5,1.1 \mathrm{~Hz}) / \delta_{\mathrm{C}} 122.5 ; \delta_{\mathrm{H}} 6.88$ $\left.(\mathrm{dd}, J=7.7,1.6 \mathrm{~Hz}) / \delta_{\mathrm{C}} 126.4\right]$, one monosubstituted benzene moiety $\left[\delta_{\mathrm{H}} 7.34-7.39(4 \mathrm{H}, \mathrm{m}) / \delta_{\mathrm{C}} 129.5(2 \mathrm{C}), 129.1(2 \mathrm{C}) ; \delta_{\mathrm{H}} 7.27\right.$ (ddd, $\left.J=8.4,6.9,1.7 \mathrm{~Hz}) / \delta_{\mathrm{C}} 127.1\right]$, three $\mathrm{sp}^{3}$ methines $\left[\delta_{\mathrm{H}} 6.55\right.$ $\left.(\mathrm{s}) / \delta_{\mathrm{C}} 98.2 ; \delta_{\mathrm{H}} 4.82(\mathrm{~s}) / \delta_{\mathrm{C}} 70.1 ; \delta_{\mathrm{H}} 2.81(\mathrm{~m}) / \delta_{\mathrm{C}} 50.8\right]$, one $\mathrm{sp}^{3}$ methylene $\left[\delta_{\mathrm{H}} 3.06(\mathrm{dd}, J=13.8,5.5 \mathrm{~Hz}), 2.99(\mathrm{dd}, J=13.8,10.2\right.$ $\left.\mathrm{Hz}) / \delta_{\mathrm{C}} 35.9\right]$, and one methyl $\left[\delta_{\mathrm{H}} 2.82(3 \mathrm{H}, \mathrm{s}) / \delta_{\mathrm{C}} 30.2\right]$. The aforementioned functionalities accounted for nine degrees of unsaturation, the remaining ones required for two additional rings in the structure of $\mathbf{1}$.

Next, 2D NMR experiments were carried out to construct the planar structure of 1 . The ${ }^{1} \mathrm{H}^{-1} \mathrm{H}$ COSY spectrum suggested the presence of three spin systems of $\mathrm{H}_{2}-3 / \mathrm{H}-2 / \mathrm{H}-2^{\prime}, \mathrm{H}-5 / \mathrm{H}-6 / \mathrm{H}-7 / \mathrm{H}-$ 8/H-9, and $\mathrm{H}-5^{\prime} / \mathrm{H}-6^{\prime} / \mathrm{H}-7^{\prime} / \mathrm{H}-8^{\prime}$ (Fig. 2). The HMBC correlations between $\mathrm{H}-2$ and $\mathrm{C}-1, \mathrm{C}-3$ and $\mathrm{C}-4$; between the methylene $\left(\mathrm{H}_{2}-3\right)$ and C-1, C-2, C-4 and C-5/9; between $\mathrm{H}-5 / 9$ and C-3, revealed the presence of a 3-phenylpropanamide moiety in $\mathbf{1}$ (Fig. 2), which is common in amide alkaloids from the Clausena species. In addition, the HMBC correlations from $\mathrm{H}-2$ to $\mathrm{C}-3^{\prime}$, from $\mathrm{H}_{2}-3$ to $\mathrm{C}-2^{\prime}$, from the oxygenated proton $\left(\mathrm{H}-2^{\prime}\right)$ to $\mathrm{C}-1, \mathrm{C}-2, \mathrm{C}-3, \mathrm{C}-3^{\prime}, \mathrm{C}-$ $4^{\prime}$ and $\mathrm{C}-8^{\prime}$, and from $\mathrm{H}-8^{\prime}$ to $\mathrm{C}-2^{\prime}$ and $\mathrm{C}-4^{\prime}$ (Fig. 2), combined with the corresponding ${ }^{1} \mathrm{H}^{-}{ }^{1} \mathrm{H}$ COSY correlations, suggested a benzyl group is linked to the 3-phenylpropanamide at C-2. Further HMBC cross-peaks from the low-field proton $\left(\mathrm{H}-1^{\prime}\right)$ to

Table $1{ }^{1} \mathrm{H}$ NMR $(600 \mathrm{MHz})$ and ${ }^{13} \mathrm{C}$ NMR (150 MHz) spectroscopic data for compound 1 in DMSO $-d_{6}\left(\delta_{\mathrm{H}}\right.$ in ppm, $J$ in $\left.\mathrm{Hz}\right)$

\begin{tabular}{lll}
\hline Position & $\delta_{\mathrm{C}}$ & $\delta_{\mathrm{H}}$ \\
\hline 1 & $168.1 \mathrm{C}$ & \\
2 & $50.8 \mathrm{CH}$ & $2.81, \mathrm{~m}$ \\
3 & $35.9 \mathrm{CH}_{2}$ & $3.06, \mathrm{dd}, 13.8,5.5 ; 2.99, \mathrm{dd}, 13.8,10.2$ \\
4 & $138.8 \mathrm{C}$ & \\
5 & $129.5 \mathrm{CH}$ & $7.34-7.39,1 \mathrm{H}, \mathrm{m}$ \\
6 & $129.1 \mathrm{CH}$ & $7.34-7.39,1 \mathrm{H}, \mathrm{m}$ \\
7 & $127.1 \mathrm{CH}$ & $7.27, \mathrm{ddd}, 8.4,6.9,1.7$ \\
8 & $129.1 \mathrm{CH}$ & $7.34-7.39,1 \mathrm{H}, \mathrm{m}$ \\
9 & $129.5 \mathrm{CH}$ & $7.34-7.39,1 \mathrm{H}, \mathrm{m}$ \\
$1^{\prime}$ & $98.2 \mathrm{CH}$ & $6.55, \mathrm{~s}$ \\
$2^{\prime}$ & $70.1 \mathrm{CH}$ & $4.82, \mathrm{~s}$ \\
$3^{\prime}$ & $122.8 \mathrm{C}$ & \\
$4^{\prime}$ & $147.5 \mathrm{C}$ & \\
$5^{\prime}$ & $117.2 \mathrm{CH}$ & $6.91, \mathrm{dd}, 8.2,1.1$ \\
$6^{\prime}$ & $130.0 \mathrm{CH}$ & $7.24, \mathrm{~m}$ \\
$7^{\prime}$ & $122.5 \mathrm{CH}$ & $6.98, \mathrm{td}, 7.5,1.1$ \\
$8^{\prime}$ & $126.4 \mathrm{CH}$ & $6.88, \mathrm{dd}, 7.7,1.6$ \\
$\mathrm{~N}^{\prime} \mathrm{CH}_{3}$ & $30.2 \mathrm{CH}$ & $2.82, \mathrm{~s}$
\end{tabular}
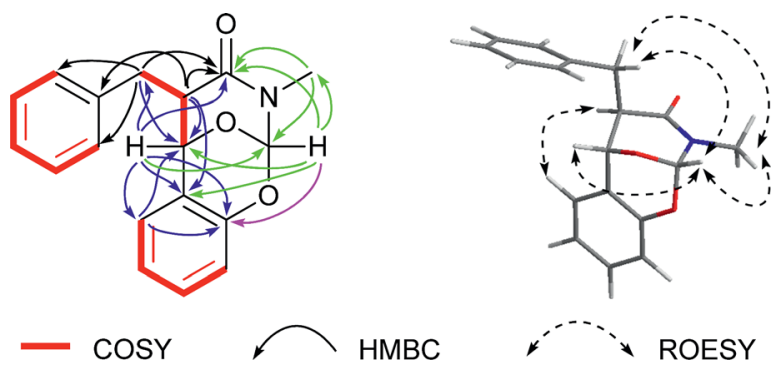

Fig. 2 Key ${ }^{1} \mathrm{H}-{ }^{1} \mathrm{H}$ COSY, HMBC and ROESY correlations of 1.

$\mathrm{C}-1, \mathrm{C}-2^{\prime}, \mathrm{C}-3^{\prime}$ and the methyl, from $\mathrm{H}-2^{\prime}$ to $\mathrm{C}-1^{\prime}$, and the methyl to $\mathrm{C}-1$ and $\mathrm{C}-1^{\prime}$ (Fig. 2), constructed a 1,3-oxazinan-4-one ring, possessing a methyl group on the nitrogen. Finally, the HMBC correlation from $\mathrm{H}-1^{\prime}$ to $\mathrm{C}-4^{\prime}$, in combination with the molecular formula, indicated the presence of an oxygen bridge between C$1^{\prime}$ and $\mathrm{C}-4^{\prime}$ to form another ring. Thus, the gross structure of 1 was constructed as shown in Fig. 1.

The relative configuration of $\mathbf{1}$ was inferred on the basis of analysis of ROESY spectrum (Fig. 2). The NOE correlations of $\mathrm{H}^{-}$ $1^{\prime} / \mathrm{N}-\mathrm{CH}_{3}, \mathrm{H}-1^{\prime} / \mathrm{H}-2^{\prime}, \mathrm{H}-1^{\prime} / \mathrm{H}-3$ and $\mathrm{H}-3 / \mathrm{N}-\mathrm{CH}_{3}$ suggested the cofacial relationship among $\mathrm{H}-1^{\prime}, \mathrm{H}-2^{\prime}, \mathrm{N}-\mathrm{CH}_{3}$ and the benzyl group, and the 1,3-oxazinan-4-one ring adopts a stable chair conformation. Additionally, the NOE cross-peaks between $\mathrm{H}-2$ and $\mathrm{H}-\mathrm{8}^{\prime}$ revealed these two protons are spatially close. Moreover, the ${ }^{1} \mathrm{H}$ NMR data gave no coupling constant $\left(J_{2,2^{\prime}} \approx 0 \mathrm{~Hz}\right)$ between $\mathrm{H}-2$ and $\mathrm{H}-2^{\prime}$, revealing a trans configuration of the two carbons. The absolute configuration of compound $\mathbf{1}$ was determined by comparison of the experimental ECD spectrum with the theoretical ECD spectrum predicted from quantum chemical TDDFT (time-dependent density functional theory) calculation. In the 190-400 nm region (Fig. 3), both the experimental ECD spectrum and the calculated one showed a positive first Cotton effect and a negative second Cotton effect. Therefore, qualitative analysis of the calculated and experimental ECD spectra allowed the assignments of the absolute configuration of 1 to be $2 R, 1^{\prime} S, 2^{\prime} S$, and $1^{\prime \prime} S$. Therefore, the structure of clausoxamine (1) was elucidated as shown (Fig. 1).

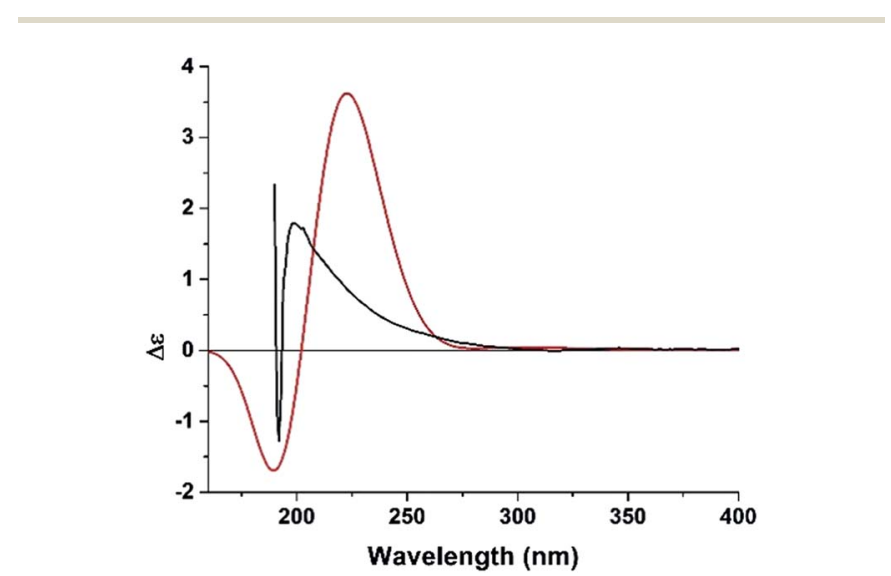

Fig. 3 Experimental (black line) and B3LYP/6-311++G(2d,2p)//B3LYP/ 6-31G(d) calculated (red line) ECD spectra of 1. 
Clausoxamine (1) is the first example of amide alkaloids possessing a 1,3-oxazinan-4-one ring. A proposed biosynthetic pathway for the formation of compound $\mathbf{1}$ was showed in Scheme 1. Compound 1 might be synthesized from the major amide alkaloid, lansiumamide B (2). The double bond in the 2phenylethenamine moiety of compound 2 could be oxidized to form epoxide ring, followed by a nucleophilic substitution reaction to form a $\gamma$-lactam ring. The intermediate I could be further oxidized to produce intermediate II. The core skeleton of 1 could be constructed by oxa-Diels-Alder reaction. Compound 1 could be formed by further double bond shift.

Six known compounds, lansiumamide B (2), ${ }^{10}(E)-N-2$-phenethyl cinnamide (3), ${ }^{11}$ lansiumamides $\mathrm{C}$ and $\mathrm{D}$ (4 and 5), ${ }^{10} \xi$ clausenamide (6), ${ }^{12}$ and SB-204900 (7) ${ }^{13}$ were isolated. Their structures were identified by comparison of the NMR and MS spectra with the reported data.

Lansiumamide B (2), the major alkaloid from the seeds of $C$. lansium, was chosen to evaluate anti-obesity and insulin sensitizing effects on high fat diet (HFD) treated mice. After eight-week HFD treatment, the body weight of mice in HFD group was significantly higher compared to that of regular chow diet (RD) group (Fig. 4A). Then, the HFD treated mice were orally administrated with lansiumamide B (HFD + LB, $20 \mathrm{mg} \mathrm{kg}^{-1}$, dissolved in PEG 400: distilled water $=6: 4, \mathrm{v} / \mathrm{v}$ ) or vehicle (PEG 400: distilled water $=6: 4, \mathrm{v} / \mathrm{v}$ ). From three weeks on, the body weight of mice from HFD + LB group was obviously reduced compared to that from HFD group (Fig. 4A). After 8 weeks treatment, the average weight gain of $13.92 \pm 4.30 \%$ was observed in HFD group against $2.02 \pm 2.82 \%$ in HFD + LB group. Analyses of the percentage of different tissue mass by total body weight revealed that the lower body weight of mice in HFD + LB group was mainly due to the reduced visceral (epididymal) and subcutaneous (inguinal) fat tissues, but not liver or kidney (Fig. 4B). Obesity is always accompanied by elevated lipid in serum, resulting in insulin resistance and type 2 diabetes. Therefore, the serum lipid profile was analyzed. As expected, the serum cholesterol and LDL were elevated in HFD-treated mice, but the serum HDL levels were unchanged (Table 2). Lansiumamide B treatment significantly reversed the increases of serum cholesterol and LDL levels (Table 2). Similarly, the cholesterol and LDL were increased, and HDL was decreased in liver from HFD-treated mice, compared with those of RD mice; while, lansiumamide B treatment almost reversed these changes (ESI Table S1 $\dagger$ ). Furthermore, q-RT-PCR analysis revealed HFD treatment elevated the expressions of

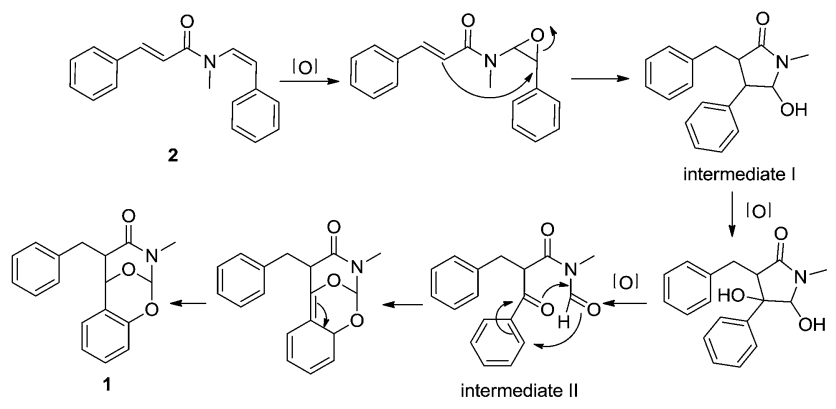

Scheme 1 Proposed biosynthetic pathway for 1.
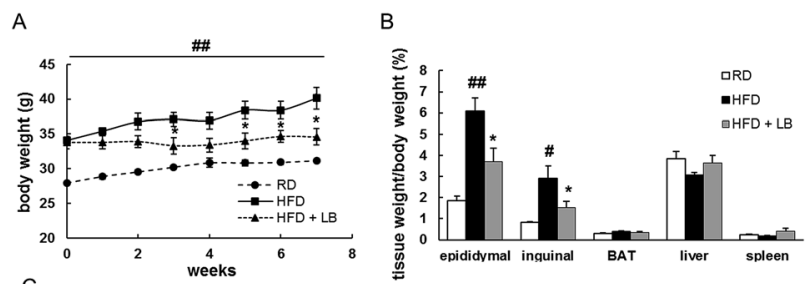

C
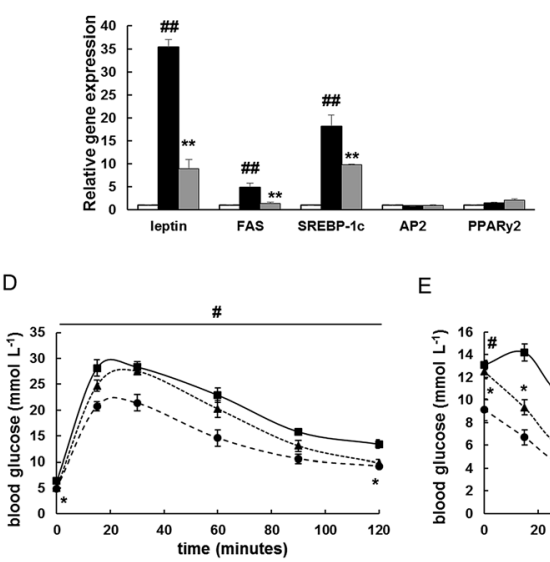

E

Fig. 4 Effects of lansiumamide B on high fat diet induced obesity and insulin resistance in mice. (A) Body weight change of mice. (B) Tissue index of mice. (C) q-RT-PCR analysis of genes in epididymal fat. (D) Glucose tolerance test after six weeks lansiumamide B treatment. (E) Insulin tolerance test after seven weeks lansiumamide B treatment. Data are shown as mean \pm S.D., $n=6, \# p<0.05$ and \#\#p $<0.001 \mathrm{RD}$ vs. HFD group of mice. ${ }^{*} p<0.05, * * p<0.001$, HFD + LB vs. HFD group of mice.

adipokine, leptin, and lipogenic markers, FAS (fatty acid synthase) and SREBP-1c (Sterol regulatory element-binding protein 1c), but not adipogenic markers, AP2 (adipocyte protein 2) and PPAR $\gamma 2$ (Peroxisome proliferator-activated receptor $\gamma 2$ ); and lansiumamide B treatment significantly suppressed the expressions of leptin, FAS and SREBP-1c (Fig. 4C). Taken together, lansiumamide B prevented HFD-induced obesity through suppressing lipogenesis.

To assess the insulin sensitivity in lansiumamide B treated mice, glucose tolerance tests (GTT) and insulin tolerance tests (ITT) were performed. During GTT, the glucose clearance rate was greatly interrupted in HFD mice, and lansiumamide B treatment obviously improved glucose disposal rate (Fig. 4D). In ITT experiments, the glucose levels of lansiumamide B treated mice were significantly reduced under insulin stimulation, as low as those of $\mathrm{RD}$ mice, which indicated lansiumamide $\mathrm{B}$ greatly enhanced insulin sensitivity (Fig. 4E) in mice.

Table 2 Effect of lansiumamide B on serum lipid profile ${ }^{a}$

\begin{tabular}{lccc}
\hline & RD & HFD & HFD + LB \\
\hline Cholesterol $\left(\mathrm{mmol} \mathrm{L}^{-1}\right)$ & $4.85 \pm 0.90$ & $10.11 \pm 0.50^{b}$ & $7.03 \pm 0.64^{c}$ \\
HDL $\left(\mathrm{mmol} \mathrm{L}^{-1}\right)$ & $3.01 \pm 0.44$ & $3.66 \pm 0.41$ & $2.85 \pm 0.22$ \\
LDL $\left(\mathrm{mmol} \mathrm{L}^{-1}\right)$ & $0.76 \pm 0.12$ & $3.12 \pm 0.62^{b}$ & $1.63 \pm 0.28^{c}$
\end{tabular}

${ }^{a}$ Data are shown as mean \pm S.D., $n=6 .{ }^{b} p<0.05 \mathrm{RD} v s$. HFD group of mice. ${ }^{c} p<0.05$, HFD + LB vs. HFD group of mice. 
Collectively, lansiumamide B effectively improved HFD induced insulin resistance.

\section{Conclusions}

In conclusion, one novel alkaloid was identified from the seeds of $C$. lansium. To the best of our knowledge, compound $\mathbf{1}$ is the first example of alkaloid from the genus Clausena, containing a 1,3-oxazinan-4-one ring. Furthermore, lansiumamide B, a major alkaloid from C. lansium, showed potential anti-obesity effect on HFD treated mice, which might be developed as an anti-obesity agent.

\section{Experimental section}

\section{General experimental procedures}

Optical rotation data were obtained using an Autopol VI polarimeter. UV data were recorded with a Varian Cary 50 spectrophotometer. ECD spectra were recorded with a JASCO J-810 circular dichroism spectrophotometer. IR spectra were recorded on a PerkinElmer spectrum-100 FTIR spectrometer using KBr disks. NMR spectra were recorded on an ASCEND $600 \mathrm{MHz} /$ $54 \mathrm{~mm}$ NMR spectrometers. The chemical shift $(\delta)$ values were given in ppm with TMS as internal standard, and coupling constants $(J)$ were in Hz. ESIMS and HRESIMS spectra were recorded on an LTQ-Orbitrap XL spectrometer. All solvents were analytical grade (Tianjing Chemical Plant, Tianjing, People's Republic of China). Silica gel used for flash chromatography and precoated silica gel GF254 plates used for TLC were produced by Qingdao Haiyang Chemical Co., Ltd. TLC spots were viewed at $254 \mathrm{~nm}$ and visualized by spraying with $10 \%$ sulfuric acid in alcohol. MCI gel (CHP20P, 75-150 $\mu \mathrm{m}$, Mitsubishi Chemical Industries Ltd., Tokyo, Japan) and Sephadex LH20 gel (GE Healthcare Life Sciences, Buckinghamshire, UK) were used for column chromatography (CC). Preparative HPLC was performed on a Shimadzu LC-20AP instrument with a SPDM20A PDA detector. Chromatographic separation was carried out on a C18 column $\left(19 \times 250 \mathrm{~mm}, 5 \mu \mathrm{m}\right.$, Waters, SunFire $\left.{ }^{\mathrm{TM}}\right)$, using a gradient solvent system comprised of $\mathrm{H}_{2} \mathrm{O}$ (A) and $\mathrm{CH}_{3} \mathrm{CN}(\mathrm{B})$ at a flow rate of $10 \mathrm{~mL} \mathrm{~min}{ }^{-1}$.

\section{Plant material}

The seeds of $C$. lansium were collected from Lincheng, Qinzhou, Guangxi Zhuang Autonomous Region, People's Republic of China, in August 2015, and identified by Professor Jingui Shen from Shanghai Institute of Materia Medica, Chinese Academy of Sciences. A voucher was deposited at the herbarium of the Institute of Chinese Medical Sciences, University of Macau (LL20151002).

\section{Extraction and isolation}

The air-dried seeds of C. lansium $(2.5 \mathrm{~kg})$ were ground into powder and defatted with petroleum ether $(1.5 \mathrm{~L})$ for three times. The residues were then extracted with $95 \%$ ethanol under reflux for 3 hours $(2 \mathrm{~L} \times 3$ times). After evaporation of the collected percolate, the crude extract (120 g) was suspended in
$400 \mathrm{~mL} \mathrm{H}_{2} \mathrm{O}$ and extracted with EtOAc $(250 \mathrm{~mL} \times 3$ times) and $n$-butanol ( $250 \mathrm{~mL} \times 3$ times), successively. The EtOAc fraction $(27.7 \mathrm{~g})$ was subjected to CC over silica gel eluted with petroleum ether/acetone $(20: 1$ to $1: 1, \mathrm{v} / \mathrm{v})$, to yield eight major fractions (A to $\mathrm{H}$ ). Compound $2(2.4 \mathrm{~g})$ was crystallized from subfraction C. Fraction D was subjected to CC over silica gel, eluted with $\mathrm{CHCl}_{3}$-EtOAc (10:1 to $\left.3: 1, \mathrm{v} / \mathrm{v}\right)$ to yield six subfractions (D1 to D6). Fraction D5 was further purified by preparative HPLC, eluting with $\mathrm{H}_{2} \mathrm{O} / \mathrm{CH}_{3} \mathrm{CN}(1: 1, \mathrm{v} / \mathrm{v})$, to obtain compound $3(8.6 \mathrm{mg})$. Fraction $\mathrm{F}$ was purified with Sephadex LH-20, eluting with $\mathrm{CHCl}_{3} / \mathrm{CH}_{3} \mathrm{OH}(1: 1, \mathrm{v} / \mathrm{v})$ to yield three fractions (F1 to F3). F3 was further separated by preparative HPLC, eluting with $\mathrm{H}_{2} \mathrm{O} / \mathrm{CH}_{3} \mathrm{CN}(3: 7$ to $0: 1, \mathrm{v} / \mathrm{v})$, to obtain compound 7 ( $9.6 \mathrm{mg}$ ) and a mixture of $4 / 5(13.2 \mathrm{mg})$. Fraction $\mathrm{G}$ was also purified with Sephadex LH-20, eluting with $\mathrm{CHCl}_{3} /$ $\mathrm{CH}_{3} \mathrm{OH}(1: 1, \mathrm{v} / \mathrm{v})$ to yield five fractions (G1 to G5). Compound 6 $(4.2 \mathrm{mg})$ was obtained from fraction G2 by preparative HPLC, eluting with $\mathrm{H}_{2} \mathrm{O} / \mathrm{CH}_{3} \mathrm{CN}(1: 1$ to $0: 1$, v/v). Fraction $\mathrm{G}$ was subjected to $\mathrm{CC}$ over silica gel, eluted with petroleum etheracetone (10:1 to $1: 1, \mathrm{v} / \mathrm{v}$ ), to yield six subfractions (G1 to G6). Compound $1(5.7 \mathrm{mg})$ was purified from fraction $\mathrm{G} 2$ by preparative HPLC, eluding with $\mathrm{H}_{2} \mathrm{O} / \mathrm{CH}_{3} \mathrm{CN}(1: 1, \mathrm{v} / \mathrm{v})$.

Clausoxamine (1). White amorphous powder; $[\alpha]_{\mathrm{D}}^{20}=+13.0(c$ 0.02 in $\left.\mathrm{CH}_{3} \mathrm{OH}\right)$; $\mathrm{UV}\left(\mathrm{CH}_{3} \mathrm{OH}\right) \lambda_{\max }(\log \varepsilon) 211$ (1.13), 271 (0.22) nm; IR (KBr) $v_{\max } 2922,1658,1491,1459,1254,1216$, 1194, 1033, $977 \mathrm{~cm}^{-1}$; NMR data see Table 1; HRESIMS $\mathrm{m} / \mathrm{z}$ $296.1261[\mathrm{M}+\mathrm{H}]^{+}$(calcd for $\mathrm{C}_{18} \mathrm{H}_{18} \mathrm{NO}_{3}, 296.1287$ ).

\section{Computational methods}

Conformational analysis of $\mathbf{1}$ was carried out via Monte Carlo searching using molecular mechanism with MMFF94 force field in the Spartan 08 program. ${ }^{14}$ The result showed three lowest energy conformers for $\mathbf{1}$. The conformers were then reoptimized using DFT at the B3LYP/6-31+G(d) level in vacuum in the Gaussian 09 program. ${ }^{15}$ The $\mathrm{B} 3 \mathrm{LYP} / 6-31+\mathrm{G}(\mathrm{d})$ harmonic vibrational frequencies were further calculated to confirm their stability. The energies, oscillator strengths, and rotational strengths of the first 60 electronic excitations were calculated using the TDDFT methodology at the B3LYP/6-311++G(2d,2p) level in vacuum. The ECD spectra were then simulated by the overlapping Gaussian function $(\sigma=0.70 \mathrm{eV}),{ }^{16}$ in which velocity rotatory strengths of the first 20 exited states were adopted. To get the conformationally averaged ECD spectra, the simulated spectra of the lowest energy conformers were averaged according to the Boltzmann distribution theory and their relative Gibbs free energy $(\Delta G)$.

\section{Animals}

All animal experiments were approved by the Animal Ethical and Welfare Committee of University of Macau (No. ICMS-AEC2014-06). All procedures involved in the animal experiments were carried out in accordance with the approved guidelines and regulations. Male $\mathrm{C} 57 \mathrm{BL} / 6 \mathrm{~J}$ mice were purchased from the animal facility of Faculty of Health Sciences, University of Macau, and maintained at $22 \pm 1{ }^{\circ} \mathrm{C}$ under a $12 \mathrm{~h}$ light, $12 \mathrm{~h}$ dark cycle with a $50 \%$ humidity, free access to food and water. 


\section{Lansiumamide B treatment}

Eight-week-old male mice were randomly distributed into three groups, each six mice. One group of mice (RD) were fed with a regular chow-diet (Guangdong Medical Lab Animal Centre, Guangzhou, Guangdong, People's Republic of China). The other two groups of mice were fed with a $45 \%$ high fat diet (Trophic Animal Feed High-Tech Co., Nantong, Jiangsu, People's Republic of China) for eight weeks to induce obesity. Then, one group of the high fat diet treated mice (HFD + LB) were orally administrated with $20 \mathrm{mg} \mathrm{kg}{ }^{-1}$ lansiumamide B (dissolved in PEG $400:$ distilled water $=6: 4, \mathrm{v} / \mathrm{v}$ ) once a day for eight weeks. The other group of the high fat diet treat mice (HFD) and the RD group of mice were orally administrated with the same volume of vehicle solution (PEG $400:$ distilled water $=6: 4, \mathrm{v} / \mathrm{v}$ ) once a day for eight weeks. Body weight was monitored every week. Tissues and serum were collected after 16 hour of fasting and stored at $-80{ }^{\circ} \mathrm{C}$ for further studies.

\section{Analysis of serum lipids}

Triglycerides HDL and LDL levels in serum and liver were analysed using commercially available kits (Nanjing Jiancheng, Nanjing, Jiangsu, People's Republic of China), following the manufacture's instruction.

\section{q-RT-PCR analysis}

Total RNA of epididymal fat was isolated using TRIzol Reagent (Invitrogen, Carlsbad, CA) following the manufacturer's instructions. The cDNA was synthesized from $1 \mu \mathrm{g}$ RNA using the SuperScript III First-Strand Synthesis System for RT-PCR (Invitrogen). Q-PCR was performed on a Bio-Rad qPCR machine using the SYBR Green PCR Master Mix, according to the manufacturer's recommended procedures. The primers were as follows: leptin forward primer $5^{\prime}$-CTATCCAGAAAGTCCAGGATGACA-3', leptin reverse primer $5^{\prime}$-ATTCTCCAGGTCATTGGCTATCT- $3^{\prime}$; adiponectin forward primer $5^{\prime}$-GTTCCTCTTAATCCTGCCCAGTC-3', adiponectin reverse primer $5^{\prime}$-GATCTTAGTAAAGCGAATGGGTACA- $3^{\prime}$; resistin forward primer $5^{\prime}$-GAACTGAGTTGTGTCCTGCTAAGTC- ${ }^{\prime}$, resistin reverse primer $5^{\prime}$ AATTTAAGCCAATGTTCTTTATTGC- ${ }^{\prime}$; FAS forward primer $5^{\prime}$ AGAGATCCCGAGACGCTTCT-3', FAS reverse primer $5^{\prime}$ GCCTGGTAGGCATTCTGTAGT-3'; SREBP-1c forward primer $5^{\prime}$ GGAGCCATGGATTGCACATT-3', SREBP-1c reverse primer $5^{\prime}$ CCTGTCTCACCCCCAGCATA-3'; AP2 forward primer $5^{\prime}$-AGTGAAAACTTCGATGATTACATGAA-3', AP2 reverse primer $5^{\prime}$ GCCTGCCACTTTCCTTGTG-3'; PPAR $\gamma 2$ forward primer $5^{\prime}$ GCCTATGAGCACTTCACAAGAAATT- $3^{\prime}$, PPAR $\gamma 2$ reverse primer $5^{\prime}$ TGCGAGTGGTCTTCCATCAC-3'. 18S was used as housekeeping gene: $18 \mathrm{~S}$ forward primer $5^{\prime}$-AGCCTGCGGCTTAATTTGAC-3' ${ }^{\prime}$, 18S reverse primer $5^{\prime}$-CAACTAAGAACGGCCATGCA- $3^{\prime}$.

\section{Glucose tolerance tests and insulin tolerance tests}

The glucose tolerance tests (GTT) and insulin tolerance tests (ITT) were performed after six and seven weeks of lansiumamide B treatment, respectively, as described previously. ${ }^{17,18}$ After 18 hours fasting, the tail blood glucose was measured using
OneTouch Ultra blood glucose meter and LifeScan test strips. Then, the mice were received an intraperitoneal injection of glucose solution (Sigma-Aldrich, St. Louis, MO, USA) at a dose of $2.0 \mathrm{~g} \mathrm{~kg}^{-1}$ body weight. The tail blood glucose was measured at 15, 30, 60 and $120 \mathrm{~min}$ after injections. Regarding to ITT, the mice tail blood glucose concentration was measured after 6 hours fasting. The mice were then received an intraperitoneal injection of human insulin (Eli Lilly, Indianapolis, IN, USA) at a dose of $1.0 \mathrm{U} \mathrm{kg}^{-1}$ of body weight. Tail blood glucose concentration was measured at 15, 30, 60, 90 and 120 min after injections.

\section{Statistical analysis}

Data were presented as mean values and standard errors of the mean. Statistical analyses were performed using one-way ANOVA statistical analysis, Graphpad Prism version 6.0. ${ }^{*} p<$ 0.05 was considered statistically significant.

\section{Conflicts of interest}

There are no conflicts to declare.

\section{Acknowledgements}

Financial support by the Science and Technology Development Fund, Macao S. A. R (FDCT 120/2013/A3) and the Research Fund of University of Macau (MYRG2015-00153-ICMS-QRCM, and MYRG2017-00109-ICMS) are gratefully acknowledged. The authors thank Prof. Jingui Shen for identification of plant material.

\section{Notes and references}

1 S. E. Kahn, R. L. Hull and K. M. Utzschneider, Nature, 2006, 444, 840-846.

2 D. M. Muoio and C. B. Newgard, Nat. Rev. Mol. Cell Biol., 2008, 9, 193-205.

3 H. L. Daneschvar, M. D. Aronson and G. W. Smetana, Am. J. Med., 2016, 129, e871-e876.

4 A. C. Adebajo, E. O. Iwalewa, E. M. Obuotor, G. F. Ibikunle, N. O. Omisore, C. O. Adewunmi, O. O. Obaparusi, M. Klaes, G. E. Adetogun, T. J. Schmidt and E. J. Verspohl, J. Ethnopharmacol., 2009, 122, 10-19.

5 D.-Y. Shen, C.-H. Chao, H.-H. Chan, G.-J. Huang, T.-L. Hwang, C.-Y. Lai, K.-H. Lee, T.-D. Thang and T.-S. Wu, Phytochemistry, 2012, 82, 110-117.

6 T. Matsui, C. Ito, H. Furukawa, T. Okada and M. Itoigawa, Inflammation Res., 2013, 62, 333-341.

7 D.-Y. Shen, Y.-Y. Chan, T.-L. Hwang, S.-H. Juang, S.-C. Huang, P.-C. Kuo, T.-D. Thang, E.-J. Lee, A.-G. Damu and T.-S. Wu, J. Nat. Prod., 2014, 77, 1215-1223.

8 K. N. Prasad, H.-H. Xie, J. Hao, B. Yang, S.-X. Qiu, X.-Y. Wei, F. Chen and Y.-M. Jiang, Food Chem., 2010, 118, 62-66.

9 H.-Y. Jiang, C.-F. Wang, L. Fang, K. Yang, J.-B. Feng, Z.-F. Geng, J. Xu, Z.-W. Deng, S.-S. Du and H.-B. Yin, Molecules, 2013, 18, 10768-10775. 
10 J.-H. Lin, Phytochemistry, 1989, 28, 621-622.

11 H.-Y. Yao, Y. Tang and K. Yamamoto, Tetrahedron Lett., 2012, 53, 5094-5098.

12 M.-H. Yang, Y.-Y. Chen and L. Huang, Acta Chim. Sin., 1987, 45, 1170-1174.

13 P. H. Milner, N. J. Coates, M. L. Gilpin, S. R. Spear and D. S. Eggleston, J. Nat. Prod., 1996, 59, 400-402.

14 Wavefunction Inc, Spartan 08, Irvine, CA.

15 M. J. Frisch, G. W. Trucks, H. B. Schlegel, G. E. Scuseria, M. A. Robb, J. R. Cheeseman, G. Scalmani, V. Barone, B. Mennucci, G. A. Petersson, H. Nakatsuji, M. Caricato, X. Li, H. P. Hratchian, A. F. Izmaylov, J. Bloino, G. Zheng, J. L. Sonnenberg, M. Hada, M. Ehara, K. Toyota, R. Fukuda, J. Hasegawa, M. Ishida, T. Nakajima, Y. Honda, O. Kitao, H. Nakai, T. Vreven, J. A. Montgomery Jr, J. E. Peralta, F. Ogliaro, M. Bearpark, J. J. Heyd, E. Brothers, K. N. Kudin, V. N. Staroverov, R. Kobayashi,
J. Normand, K. Raghavachari, A. Rendell, J. C. Burant, S. S. Iyengar, J. Tomasi, M. Cossi, N. Rega, J. M. Millam, M. Klene, J. E. Knox, J. B. Cross, V. Bakken, C. Adamo, J. Jaramillo, R. Gomperts, R. E. Stratmann, O. Yazyev, A. J. Austin, R. Cammi, C. Pomelli, J. W. Ochterski, R. L. Martin, K. Morokuma, V. G. Zakrzewski, G. A. Voth, P. Salvador, J. J. Dannenberg, S. Dapprich, A. D. Daniels, Ö. Farkas, J. B. Foresman, J. V. Ortiz, J. Cioslowski and D. J. Fox, Gaussian 09 Rev. C01, Gaussian, Inc, Wallingford CT, 2009.

16 P. J. Stephens and N. Harada, Chirality, 2010, 22, 229-233.

17 J.-H. Lee, L.-G. Lin, P.-W. Xu, K. Saito, Q. Wei, A. G. Meadows, O. Y. Bongmba, G. Pradhan, H. Zheng, Y. Xu and Y.-X. Sun, Diabetes, 2016, 65, 2169-2178.

18 X.-J. Ma, L.-G. Lin, J. Yue, C.-S. Wu, C.-A. Guo, R.-T. Wang, K.-J. Yu, S. Devaraj, P. Murano, Z. Chen and Y.-X. Sun, Int. J. Mol. Sci., 2017, 18, 1302. 